\title{
Diagnóstico laboratorial e monitoramento das doenças osteometabólicas
}

\section{Laboratory diagnosis and follow-up in osteometabolic diseases}

José Gilberto Henriques Vieira

\begin{abstract}
unitermos resumo
Doenças osteometabólicas

Poucas áreas de diagnóstico laboratorial apresentaram evolução recente mais acelerada do que os testes para o diagnóstico e monitoramento das doenças osteometabólicas. Novos conhecimentos sobre fisiopatologia, além de novidades nas modalidades terapêuticas e nos testes diagnósticos tornaram o campo na área de diagnósticos muito mais complexo, efetivo e interessante. O diagnóstico diferencial das hiper e hipocalcemias, assim como a definição e o seguimento da terapêutica para osteoporose são duas áreas onde progressos sensíveis puderam ser constatados. Por outro lado, o aproveitamento de todo esse potencial exige dos profissionais que atuam na área um conhecimento cada vez maior, de forma que o emprego dos novos testes seja feito com eficácia e coerência.
\end{abstract}

Few areas in the clinical laboratory field presented a more accelerated recent evolution than that of the tests for diagnosis and monitoring of osteometabolic diseases. Newer knowledge about physiopathology, newer therapeutic modalities and new diagnostic tests, turned this field much more complex, effective and interesting. The differential diagnosis of hyper and hypocalcemia and the definition and follow-up of osteoporosis therapeutics, are two of the areas where a more significant progress has been made. On the other side, the good use of all this potential asks the professionals working in this area an even deeper knowledge, so that the new tests are employed with efficacy and coherence.

key words

Osteometabolic diseases

Osteoporosis

Hypercalcemia

Hypocalcemia

Bone metabolic markers

\section{Introdução}

Os ossos são compostos de um tecido metabolicamente ativo com duas funções básicas para o organismo: uma mecânica e outra bioquímica. Em função disso e seguindo vários sistemas de controle, sofre um processo contínuo de renovação e remodelação. Essa atividade é conseqüência, em sua maior parte, da ação de dois tipos celulares principais, característicos do tecido ósseo: os osteoblastos e os osteoclastos. O processo de remodelação óssea se desenvolve com base em dois processos antagônicos, mas intimamente acoplados: a formação e a reabsorção ósseas. O acoplamento dos dois processos permite a renovação e a remodelação ósseas e é mantido em longo prazo por um complexo sistema de controle, que inclui hormônios e fatores locais. Uma série de condições, como idade, doenças osteometabólicas, mobilidade diminuída, ação de drogas, entre outras, pode alterar esse equilíbrio entre a formação e a reabsorção, levando ao predomínio de um sobre o outro.

Médico assessor em Endocrinologia do Laboratório Fleury; professor afiliado da Disciplina de Endocrinologia da Escola Paulista de Medicina da Universidade Federal de São Paulo (EPM/UNIFESP). 
A anamnese bem feita, mais exame clínico cuidadoso, ainda são as peças mais importantes no diagnóstico. A partir dos dados levantados pelo clínico, são indicados os exames necessários para a confirmação diagnóstica. É desnecessário lembrar a economia de recursos que uma anamnese e um exame clínico podem trazer, especialmente numa área onde os testes diagnósticos são, muitas vezes, complexos e dispendiosos.

Na última década nossos conhecimentos sobre fisiologia e patologia ósseas evoluíram de maneira considerável. Novas metodologias diagnósticas e novos esquemas terapêuticos, bem como o crescente acúmulo de conhecimentos sobre as patologias mais prevalentes e sua evolução na população, tornam a investigação laboratorial das doenças osteometabólicas um processo cada vez mais abrangente e complexo. A seguir, procuraremos apresentar os principais métodos disponíveis em laboratórios clínicos e discutir os fatos mais importantes que impactam sua realização e interpretação.

\section{Principais testes laboratoriais disponíveis}

Pelo fato de as principais patologias osteometabólicas serem, muitas vezes, oligo ou assintomáticas em sua fase inicial, período em que a intervenção terapêutica seria mais conveniente, o emprego de métodos laboratoriais e/ou de imagem é fundamental.

Do ponto de vista laboratorial, os principais testes são as dosagens de cálcio e fósforo séricos e urinários. Elas constituem o elemento básico de diagnóstico de qualquer doença osteometabólica. Embora sejam dosagens de rotina em qualquer laboratório de patologia clínica, sua determinação merece uma série de considerações metodológicas.

\section{Cálcio sérico}

O cálcio sérico circula sob duas formas principais: o cálcio ionizado (que exerce a ação biológica) e o cálcio ligado a proteínas e complexado. O primeiro corresponde, em circunstâncias normais, a $52 \%$ do total e o segundo a $48 \%$. É evidente que qualquer alteração do nível de proteínas séricas, em especial da albumina, leva à alteração do conteúdo total de cálcio no soro, sem que isso implique numa alteração da fração ionizada. Vale aqui o mesmo raciocínio desenvolvido quando se discute avaliação de hormônios livres. Outro fator que leva a alterações das porcentagens entre o cálcio ionizado e o ligado é a concentração de íon hidrogênio (pH), mas na acidose há tendência a uma menor ligação do cálcio às proteínas. Em vista disso, em uma série de circunstâncias clínicas, a dosagem de cálcio total não fornece informação fidedigna quanto à calcemia funcional.

Diversas equações foram desenvolvidas para a correção dos valores do cálcio total no que se refere às alterações do conteúdo protéico, sendo a mais usada a proposta por McLean e Hastings ${ }^{(19)}$. As metodologias automatizadas atualmente disponíveis são tecnicamente bastante confiáveis, contudo os valores de referência mais aceitos situam-se entre 8,6 e 8,8 mg/dl para o limite inferior, e 10,2 e 10,3 $\mathrm{mg} / \mathrm{dl}$ para o limite superior da normalidade.

Com a maturação da tecnologia de determinação de cálcio ionizado utilizando eletrodos íon-específicos ${ }^{(7)}$, na prática ficou evidente o maior poder diagnóstico dessa determinação, que deve ser a preferida, quando disponível. A dosagem de cálcio ionizado tem se mostrado extremamente útil, não só nos casos de hipercalcemia, como também nos de hipocalcemia, pois podem ser diagnosticados com rapidez e segurança, melhorando significativamente a qualidade do atendimento médico, especialmente os de urgência e em ambiente hospitalar.

Um inconveniente em relação à determinação de cálcio ionizado se refere à coleta, pois o material deve ser tratado de maneira diferenciada. No caso das dosagens em sangue total, a coleta deve ser idealmente feita em seringas com heparina especial (titulada com cálcio para evitar quelação). Já no caso de dosagens séricas, o sangue deve ser colhido em tubo a vácuo, o soro separado rapidamente e se for estocado, deve-se minimizar o contato com ar, mas é necessário congelar a amostra. O ideal é a realização imediata da dosagem, o que constitui outra vantagem adicional dos métodos íon-específicos, pois o resultado é obtido rapidamente.

Os aparelhos mais recentes de determinação de cálcio ionizado medem concomitantemente o pH da amostra e fornecem os valores do cálcio ionizado medido e o corrigido para pH 7,4. Um aspecto adicional que merece cuidado é a definição de valores normais, em especial para os níveis de cálcio ionizado. Crianças apresentam valores mais altos do que adultos, podendo as faixas de normalidade variar de acordo com a metodologia empregada. Em levantamento abrangente sobre condições de coleta e valores de referência realizado em nosso meio, obteve-se o intervalo entre $1,11 \mathrm{mmol} / \mathrm{l} \mathrm{e} 1,40 \mathrm{mmol} / \mathrm{/}^{(3)}$.

\section{Cálcio urinário}

A excreção urinária de cálcio é de grande importância no diagnóstico e seguimento de inúmeras patologias 
osteometabólicas. Do ponto de vista prático pode ser expressa como valor absoluto de 24 horas e/ou em relação ao filtrado glomerular em amostra isolada. As duas formas de expressão da calciúria têm aplicações distintas. Assim, a excreção de 24 horas reflete o equilíbrio entre a absorção do cálcio da dieta e a perda/ganho do esqueleto.

Numa dieta normal em cálcio, a excreção de 24 horas tem como limite máximo $250 \mathrm{mg}$ para o sexo feminino e $300 \mathrm{mg}$ para o masculino ${ }^{(9)}$, isso em países com ingestão entre 800 e $1.000 \mathrm{mg} / \mathrm{dia}$. No Brasil, a ingestão situa-se entre 400 e $600 \mathrm{mg} / \mathrm{dia}$ e, conseqüentemente, valores mais baixos (até um limite de $250 \mathrm{mg} / \mathrm{dia}$ ) devem ser considerados. Já a calciúria em amostra isolada deve ser coletada pela manhã, após 12 horas de jejum, desprezando-se a primeira micção, com coleta de nova amostra após 2 horas. Lembrar que o horário é importante, porque será utilizado para o cálculo do ritmo de filtração glomerular. Em princípio, essa dosagem não é influenciada pela dieta, sendo uma representação mais fidedigna da perda óssea de cálcio. O valor de referência é bastante discutido, mas o limite de 0,100 mg/dl de filtrado glomerular é o mais aceito para a nossa população.

\section{Fósforo sérico e urinário}

O fósforo circula basicamente em duas formas: uma orgânica composta principalmente de fosfolipídios e outra inorgânica (a usualmente medida) que em adultos apresenta uma concentração média de $4 \mathrm{mg} / \mathrm{dl}$. Em razão de os níveis de fósforo apresentarem variações importantes com as refeições e ritmo circadiano significativo, é fundamental que as amostras sejam coletadas de manhã e em jejum. Outro dado importante é o fato de que os níveis séricos de fósforo inorgânico devem ser interpretados levando-se em conta a faixa da normalidade referente à idade do paciente. Em crianças a concentração é significativamente mais alta, estabilizando na idade adulta e apresentando discreto declínio na terceira idade. Já a excreção urinária de fósforo apresenta variações bastante significativas, sendo dependente principalmente da dieta. O valor-limite de $1 \mathrm{~g}$ por 24 horas é considerado como a referência superior da normalidade.

\section{Dosagem do paratormônio}

A dosagem de paratormônio (PTH) no soro tem uma longa história, iniciada, do ponto de vista do desenvolvimento metodológico, na década de 1960 . Foi uma das dosagens em que o desenvolvimento da metodologia propiciou maior conhecimento sobre o hormônio, que por sua vez levou a novos desenvolvimentos metodológicos e assim sucessivamente. Os primeiros métodos descritos eram ensaios carboxiterminal específicos ${ }^{(4)}$, os quais apresentavam como principal inconveniente o fato de que estavam sujeitos a elevações inespecíficas proporcionais às possíveis alterações de função renal, por medirem uma fração hormonal cujo metabolismo depende diretamente da filtração glomerular. Além disso, a meia-vida longa desses fragmentos prejudicava seu uso em provas funcionais.

Com a descrição de que a porção biologicamente ativa do PTH concentrava-se nos primeiros aminoácidos (porção aminoterminal), chegou-se à dedução lógica de que os ensaios dirigidos para essa porção seriam os de melhor correlação clínica ${ }^{(31,32)}$. O problema com os ensaios aminoterminais foi a grande dificuldade em se obter anticorpos de afinidade suficiente para permitir a medida dos níveis de PTH nas condições fisiológicas. Apesar das dificuldades técnicas, esse ensaio se mostrou superior aos ensaios carboxiterminal específicos. As limitações dos radioimunoensaios aminoterminais específicos se prendem à sensibilidade, 0 que implica no emprego de volumes de soro significativos e num tempo de execução longo, além de, mesmo assim, não atingirem níveis ideais de sensibilidade. Esses fatores dificultavam o emprego de testes funcionais e a definição do diagnóstico etiológico nos casos de hipocalcemia a esclarecer, e de hipercalcemia humoral maligna.

Atualmente, com a disponibilidade dos ensaios imunométricos ${ }^{(21)}$, as metodologias foram bastante simplificadas e conseguiu-se então uniformidade de resultados bem aceitável, visto que, teoricamente, apenas a forma intacta do PTH, seqüência 1-84, é medida ${ }^{(30)}$. Outra vantagem das novas metodologias é o alto grau de sensibilidade, o que propiciou um grande avanço no diagnóstico diferencial das hipercalcemias.

Trabalhos recentes ${ }^{(8)}$ mostraram que, além da forma intacta 1-84, circulam formas de PTH nas quais ocorreram perdas dos primeiros aminoácidos aminoterminais, gerando formas como o peptídeo 7-84. É interessante salientar que a atividade biológica do peptídeo depende da presença dos primeiros aminoácidos, logo pequenas deleções resultam em peptídeos inativos. Provavelmente, a presença dessas formas biologicamente inativas (aparentemente) parece não ter importância diagnóstica, sendo o único cuidado atentar para os valores normais dos novos ensaios 1-84 específicos (esses não cruzam com as formas 7-84), que são proporcionalmente mais baixos ${ }^{(29)}$.

Um cuidado adicional que sempre deve ser lembrado quando da dosagem de PTH sérico se refere às condições 
de coleta. O PTH é um peptídeo de meia-vida biológica bastante curta e extremamente frágil. A coleta requer condições especiais, que incluem refrigeração imediata, centrifugação, separação do soro e congelamento rápidos. Caso essas condições não sejam seguidas, podem ser obtidos resultados falsamente baixos, com conseqüências importantes para o paciente.

\section{Dosagem dos metabólitos da vitamina D}

Do ponto de vista prático, a 25 hidroxivitamina D (25OHD) e a 1,25 diidroxivitamina $\mathrm{D}\left(1,25(\mathrm{OH})_{2} \mathrm{D}\right)$ são os únicos metabólitos da vitamina $\mathrm{D}$ com importância diagnóstica, particularmente a 25OHD. Isso porque o nível sérico da $250 H D$ é o melhor marcador da deficiência de vitamina $\mathrm{D}$ e da intoxicação exógena, razões mais freqüentes que levam à indicação de dosagem de metabólitos da vitamina.

\section{Ensaios para a medida da 250HD sérica}

Os ensaios para a medida desse metabólito são basicamente de dois tipos: os competitivos, baseados no uso do esteróide marcado e uma proteína ligadora(15), e os ensaios baseados no sistema de cromatografia líquida de alta eficiência (HPLC) e quantificação com leitura por meio do espectrofotômetro UV ou espectrometria de massas (MS)(18). Os do primeiro tipo, que podem se basear na proteína ligadora de vitamina $\mathrm{D}$ ou em anticorpos específicos, têm como vantagens a maior simplicidade, possibilidade de automação de processos e custos mais baixos. Já os do segundo tipo apresentam como vantagens a maior precisão e a possibilidade da medida separada das duas formas: 0 colecalciferol (D3) de origem endógena ou animal e o ergocalciferol (D2) de origem vegetal. O método mais utilizado atualmente são ensaios competitivos baseados em anticorpos específicos e marcadores não-radioativos. Um dos grandes temas atuais nessa área é a melhora na comparabilidade entre resultados obtidos utilizando-se diferentes metodologias(10).

Evidentemente, uma disponibilidade de dosagens empregando os métodos mais precisos e específicos (HPLC com leitura UV ou por MS) seria ideal. Qualquer que seja o método empregado, é fundamental uma definição precisa da faixa de normalidade.

\section{Ensaios para a medida de 1,25 $(\mathrm{OH})_{2}$ D sérica}

De todos os hormônios esteróides, a dosagem da 1,25 $(\mathrm{OH})_{2}$ D é a que apresenta maiores dificuldades. Essa tem base na instabilidade do esteróide e nas concentrações sé- ricas que são, em média, mil vezes inferiores às da 25OHD. Os métodos mais empregados são competitivos e requerem processo preparativo complexo ${ }^{(23)}$, estando disponíveis apenas em laboratórios especializados.

\section{Marcadores bioquímicos do metabolismo ósseo}

Avanços recentes no isolamento e na caracterização das células e dos componentes extracelulares da matriz óssea resultaram no desenvolvimento de métodos para a medida sérica e/ou urinária de novos marcadores bioquímicos do metabolismo ósseo. Podemos definir marcadores bioquímicos do metabolismo ósseo como substâncias que retratam a formação ou a reabsorção ósseas. Como a formação depende da ação dos osteoblastos, os marcadores de formação, na realidade, medem produtos decorrentes da ação dessas células. Da mesma forma, os marcadores de reabsorção medem a ação dos osteoclastos, o principal tipo celular envolvido na reabsorção da matriz óssea.

Normalmente, como o processo de formação é estreitamente ligado ao de reabsorção, um marcador que reflete reabsorção também refletirá formação. Isso quando o tecido ósseo está em equilíbrio, como em um indivíduo hígido durante a terceira e quinta décadas de vida. No período de vida adulta, a atividade metabólica óssea e, conseqüentemente, os níveis dos marcadores tendem a apresentar valores mais baixos que os observados na infância e adolescência ${ }^{(22)}$. Durante a gravidez e lactação, o metabolismo ósseo também é mais acelerado, resultando em aumento dos níveis dos marcadores de formação e reabsorção ${ }^{(27)}$. Após a menopausa, os marcadores também tendem a se elevar, com os de reabsorção apresentando incremento maior do que os de formação(17). Diferentemente, os níveis de marcadores permanecem estáveis no sexo masculino até a oitava década de vida(33).

Durante a formação óssea, a produção da matriz colágena precede a mineralização. A fase da produção de matriz colágena coincide com a maior produção de fosfatase alcalina, enquanto a mineralização coincide com a maior produção de osteocalcina ${ }^{(28)}$. Esse fenômeno pode ser observado na doença de Paget, na qual o aumento dos níveis de fosfatase alcalina óssea é proporcionalmente maior do que os de osteocalcina, sugerindo alteração na diferenciação dos osteoblastos ${ }^{(2)}$. Os estados de deficiência de vitamina $D$ também são caracterizados por alteração na diferenciação dos osteoblastos, daí o desproporcional aumento dos níveis de fosfatase alcalina observados na osteomalacia ${ }^{(11)}$.

Os principais marcadores bioquímicos do metabolismo ósseo atualmente em uso estão listados na Tabela, sendo 
divididos entre os que refletem formação e os que refletem reabsorção. As metodologias empregadas variam de acordo com o analito (composto de interesse em análise), sendo que os marcadores de reabsorção, basicamente produtos de degradação de colágeno tipo I, inicialmente eram mensurados por sistemas de HPLC com leitura fluorométrica, especificamente para piridinolina e deoxipiridinolina totais. Atualmente, imunoensaios específicos estão disponíveis para os fragmentos carboxi (CTx) e aminoterminais (NTx) do colágeno tipo I, bem como para as piridinolinas (totais e livres). Aparentemente, e em função do tipo de fenômeno estudado, dentre esse grupo de ensaios para fragmentos de degradação de colágeno tipo I não existe vantagem de algum ensaio sobre o outro.
A Figura 1 procura mostrar esquematicamente a origem dos fragmentos carboxiterminais, que são medidos por ensaio específico (CTx). Fica claro que sua presença no soro só ocorre se houver digestão de colágeno maduro. Imunoensaios também são empregados para a medida dos marcadores de formação, como o pró-peptídeo aminoterminal do pró-colágeno tipo I (PINP), o pró-peptídeo carboxiterminal do pró-colágeno tipo I (PICP), a osteocalcina e a fosfatase alcalina óssea.

\section{Discussão}

A disponibilidade de várias ferramentas diagnósticas novas, bem como o acúmulo de experiências e de conhecimentos

\title{
Tabela 1
}

\section{Marcadores bioquímicos do metabolismo ósseo}

\author{
Formação \\ Fosfatase alcalina óssea e/ou total (soro) \\ Osteocalcina (soro) \\ PINP e PICP (soro) \\ Reabsorção \\ Hidroxiprolina (urina) \\ Interligadores do colágeno (cross-links) (urina e soro) \\ Piridinolinas totais \\ Piridinolina e/ou deoxipiridinolina livre \\ N-telopeptídeo (NTx) \\ C-telopeptídeo (CTx) \\ Fosfatase ácida tartarato-resistente (soro)
}

PINP: pró-peptídeo aminoterminal do pró-colágeno tipo I; PICP: pró-peptídeo carboxiterminal do pró-colágeno tipo I.

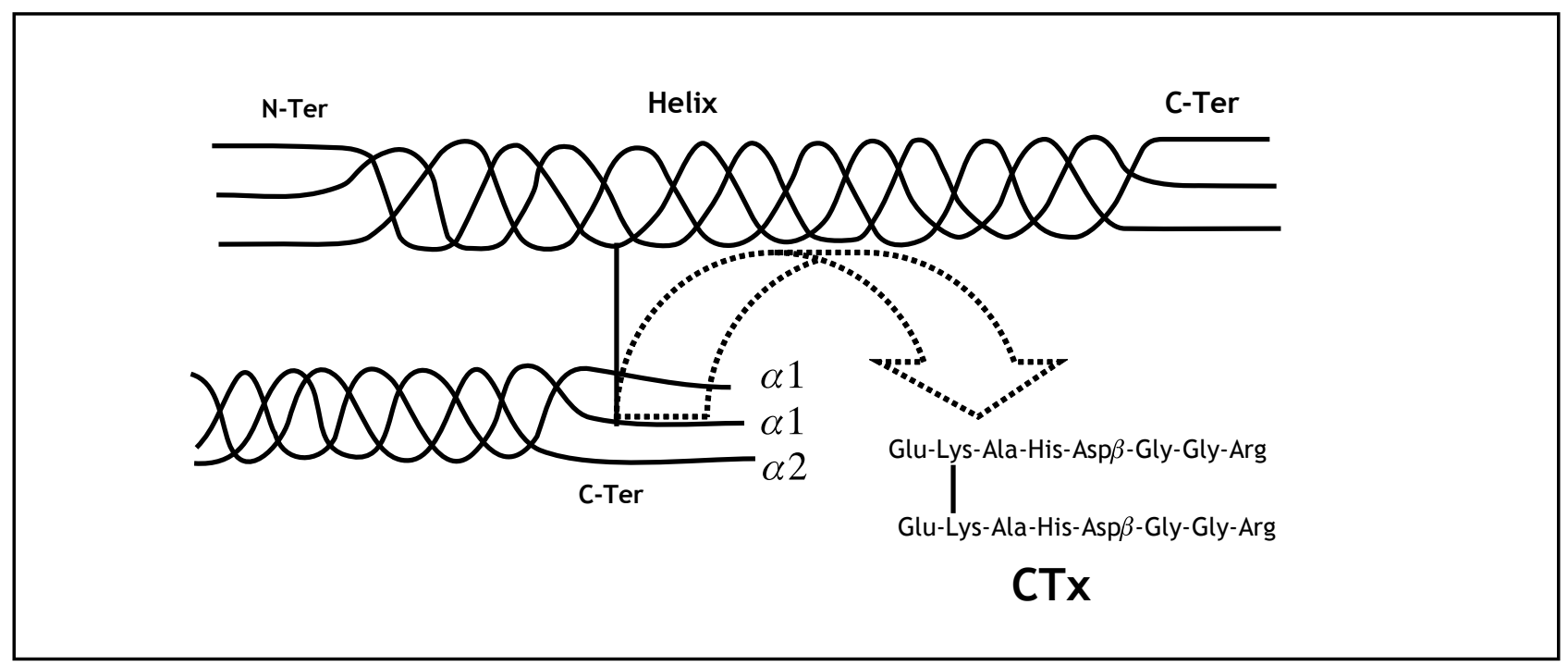

Figura 1 - Representação esquemática da origem dos fragmentos carboxiterminais do colágeno tipo I. A digestão do colágeno maduro libera peptídeos únicos originados pela associação entre as diferentes fibrilas 
sobre a fisiopatologia das doenças osteometabólicas, tornaram essa área de atuação laboratorial fascinante e ao mesmo tempo complexa. A interpretação dos dados obtidos deve levar em conta o conjunto, pois dificilmente um dado isolado é diagnóstico. Um exemplo claro é a necessidade de se interpretar um valor de PTH sempre levando em consideração os níveis da calcemia na mesma amostra.

Na Figura 2 procuramos representar de maneira esquemática todas as alternativas possíveis para os valores dos dois analitos. Vale a pena chamar a atenção para as zonas cinzentas aplicadas no retângulo central (faixa de normalidade). Elas procuram chamar a atenção para o fato de que existe correlação entre ambos os valores, de maneira que valores mais elevados de cálcio devem ser acompanhados de valores mais baixos de PTH e vice-versa. Evidentemente, essa correlação inversa é observada em condições normais, pois à medida que uma disfunção das paratireóides se instala, esse equilíbrio é rompido.

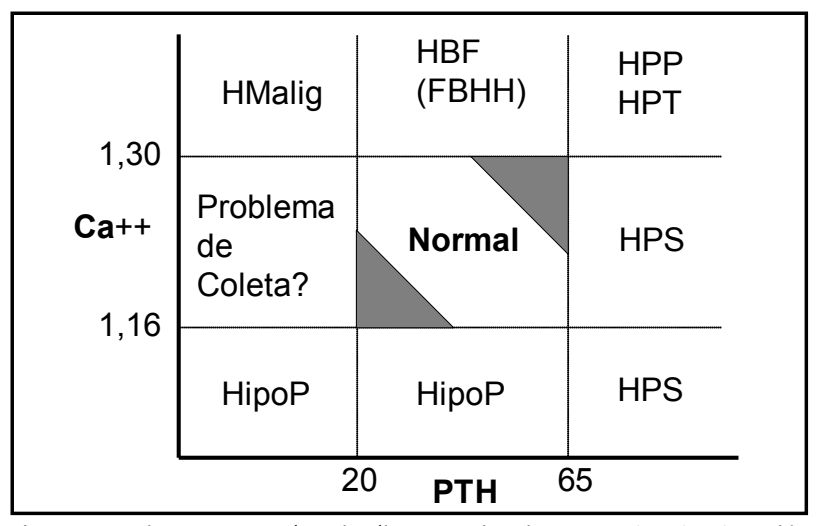

Figura 2 - Relação entre os níveis de cálcio ionizado e de paratormônio (PTH) em diferentes condições fisiopatológicas. A área cinza mostra situações onde os níveis de PTH e de cálcio normais podem na realidade representar uma condição anormal HMalig: hipercalcemia da malignidade; HBF: hipercalcemia benigna familiar; HPP: hiperparatireoidismo primário; HPT: hiperparatireoidismo terciário; HPS: hiperparatireoidismo secundário; HipoP: hipoparatireoidismo.

Caso haja indicação de hipercalcemia, o mais importante e imediato deve ser a definição se a condição é PTH dependente ou não. Para essa definição a dosagem de PTH empregando os ensaios imunométricos disponíveis é na grande maioria das vezes suficiente. $O$ encontro de calcemia elevada e níveis de PTH não-detectáveis é patognomônico de hipercalcemia não-PTH dependente, na maioria das vezes conseqüente à neoplasia ou à ingestão excessiva de vitamina $\mathrm{D}$.

Uma condição que vem adquirindo cada vez mais importância prática, em função de sua freqüência crescente, é o encontro de hiperparatireoidismo secundário à deficiência de vitamina $\mathrm{D}^{(16)}$. No caso são observados níveis normais ou pouco baixos de calcemia, com níveis elevados de PTH. É importante definir a condição, pois a conduta terapêutica difere totalmente do caso do hiperparatireoidismo primário. O mito de que num país ensolarado como o nosso essa condição seria rara vem caindo com a constatação da alta incidência de vitamina $D$ na população, em especial em idosos $^{(25)}$. A dosagem de $25 \mathrm{OHD}$ complementa o diagnóstico e pode ser útil no seguimento.

Em relação aos marcadores bioquímicos do metabolismo ósseo, outros fatores podem interferir em sua determinação. Assim, a remodelação óssea apresenta um ritmo circadiano com maiores níveis durante a noite ${ }^{(24)} \mathrm{e}$, em função disso, a primeira urina da manhã e/ou a amostra de soro colhida no início da manhã refletem o pico de reabsorção óssea e apresentarão valores seguramente mais altos do que as amostras colhidas em outro horário. Quanto aos marcadores séricos de formação, um aspecto importante a ser considerado na indicação e interpretação dos valores é a significativa diferença de meia-vida biológica entre fosfatase alcalina óssea (em torno de 1,6 dia) e osteocalcina (menos de uma hora). Logo, fenômenos agudos são mais bem representados pelos níveis de osteocalcina, enquanto os níveis de fosfatase alcalina óssea são mais estáveis e reprodutíveis, variando num prazo mais longo. Adicionalmente, os níveis de marcadores bioquímicos, principalmente os de formação óssea, variam ao longo do ciclo menstrual, sendo mais elevados durante a fase lútea, comparativamente à fase folicular ${ }^{(20)}$. Alterações importantes na função renal também podem interferir significativamente no metabolismo e excreção dos marcadores bioquímicos, principalmente da osteocalcina.

Em função de todos os aspectos discutidos, a interpretação correta dos valores de marcadores bioquímicos do metabolismo ósseo requer conhecimento das condições de coleta da amostra, bem como da condição geral do paciente. Outro aspecto interessante da relação entre cálcio e PTH é o fato de que nas condições de hipoparatireoidismo auto-imune, ou pós-cirúrgico, muitas vezes os níveis de PTH não são indetectáveis, mas inapropriados para os níveis de cálcio. Tal condição tem como base uma quantidade de tecido secretor insuficiente.

Quanto à indicação e escolha dos marcadores bioquímicos do metabolismo ósseo, em princípio eles têm indicação em qualquer circunstância em que se deseja avaliar a atividade metabólica óssea. No caso da patologia óssea mais comum, a osteoporose, utopicamente o marcador bioquímico ideal seria aquele que nos permitisse discriminar qual paciente se beneficiaria com um tratamento preventivo, e avaliar preco- 
cemente o grau de resposta à terapêutica introduzida. Quanto ao primeiro item, trabalhos recentes correlacionam o início da menopausa com aumento significativo dos marcadores bioquímicos, e esse aumento estaria relacionado a posterior perda de massa óssea ${ }^{(13)}$. Seria, portanto, possível discriminar as pacientes que evoluiriam com perda óssea aumentada daquelas que apresentariam perda óssea dentro dos limites normais para a idade e condição hormonal. Nesse sentido, todos os marcadores bioquímicos mostraram-se úteis, com possível vantagem para os interligadores de colágeno.

Vale salientar que os resultados desses estudos, e de muitos outros ${ }^{(12,26)}$, foram válidos quando analisados em conjunto, ou seja, população com perda óssea contra população sem perda óssea. A transferência dessas informações para um caso individual é muitas vezes difícil, se não impossível.

Quanto ao segundo item, ou seja, se os marcadores bioquímicos poderiam servir como sinalizadores precoces do sucesso ou insucesso de uma determinada terapia, muitas evidências indicam que sim. A necessidade, nesse caso, seria de um marcador mais precoce da ação terapêutica, desde que os efeitos retratados por mudanças na densitometria óssea são discerníveis apenas em longo prazo (mais de um ano). Atualmente há consenso de que os marcadores bioquímicos preenchem tal necessidade, independentemente do tipo de terapêutica empregada ${ }^{(1,5)}$. Os marcadores de reabsorção aparentemente respondem mais rapidamente (um mês) do que os de formação (três meses), ao tratamento com alendronato, mas a informação final é equivalente.

Estudos com agentes anabólicos (como o PTH) mostram que os marcadores de formação, especialmente o PNINP, um marcador de síntese de colágeno, são os mais informativos em estudos de curto prazo(6). Outro aspecto já bastante estudado é a correlação entre essa resposta precoce dos marcadores e a evolução da densidade mineral óssea em longo prazo ${ }^{(14)}$. Essa informação permite ao médico-assistente uma intervenção precoce na conduta terapêutica, visando otimizar os resultados sem necessidade de esperar pelas alterações densitométricas que ocorrerão em longo prazo. É importante salientar que a variação nos níveis dos marcadores bioquímicos aceita como significativa depende das variações intra-individuais intrínsecas de cada marcador. Assim, os marcadores urinários de reabsorção óssea do tipo NTx necessitam de variações acima de $30 \%$ para serem consideradas significativas, enquanto as variações dos marcadores séricos de formação e/ou de reabsorção podem ser menores, na faixa de $15 \%$ a $20 \%$.

Como último aspecto, convém salientar que afora condições específicas, como a doença de Paget, em que a fosfatase alcalina (mesmo a total) é o marcador de eleição, a escolha do marcador a ser potencialmente utilizado depende da disponibilidade, das facilidades de coleta e de armazenamento, e do custo. Com base nesse prisma, um marcador de reabsorção, especialmente o sérico (como o CTx), parece ser a dosagem mínima necessária.

\section{Conclusão}

A disponibilidade de novos testes diagnósticos, assim como a consolidação de novos conhecimentos sobre as doenças osteometabólicas, resultaram em uma nova fase no que concerne ao papel do laboratório clínico nessa importante área de diagnóstico. Os ensaios para a medida de PTH, associados à medida de cálcio sérico e, complementarmente de 25OHD, possibilitam a definição precisa das condições de hiper e hipocalcemia.

Os novos marcadores bioquímicos do metabolismo ósseo permitem uma visão clara das condições de remodelação óssea, com aplicações importantes no diagnóstico, definição terapêutica e seguimento de doenças comuns, como a osteoporose. Uma compreensão clara das bases fisiopatológicas e metodológicas desses testes laboratoriais é fundamental para seu uso criterioso e objetivo.

\section{Referências}

I.ADAMI, S. et al. Effects of oral alendronate and intranasal calcitonin on bone mass and biochemical markers of bone turnover in postmenopausal osteoporosis. Bone, v. 17, p. 383-90, 1995.

2. ALVAREZ, L.; GUANABENS, N.; PENS P. Discriminative value of biochemical markers of bone turnover in assessing the activity of Paget's disease.J Bone Miner Res, v. 10, p. 458-65, 1995.
3. ANDRIOLO, A. et al. Cálcio ionizado no soro: estimativa do intervalo de referência e condições de coleta.J Bras Patol Med Lab, v. 40, p. 85-9, 2004.

4. ARNAUD, C.D.; TSAO, H.S.; LITTLEDIKE, T. Radioimmunoassay of human parathyroid hormone in serum. J Clin Invest, v. 50, p. $21-34,1971$. 
5. BIKLE, D.D. Biochemical markers in the assessment of bone disease. Am J Med, v. 103, p. 427-36, 1997.

6. BLACK, D.M. et al. The effects of parathyroid hormone and alendronate alone or in combination in postmenopausal osteoporosis. N Engl J Med, v. 349, p. 1207-15, 2003.

7. BOWERS, G.N.; BRASSARD, C.; SENA, S.F. Measurement of ionized calcium in serum with ion-selective electrodes: a mature technology that can meet daily service needs. Clin Chem, v. 32, p. 1437-47, 1986.

8. BROSSARD, J.H. et al. Accumulation of a non-( I-84) molecular form of parathyroid hormone (PTH) detected by intact $\mathrm{PTH}$ assay in renal failure: importance in the interpretation of PTH values. J Clin Endocrinol Metab, v. 81, p. 3923-9, 1996.

9. BULUSU, L. et al. Urinary excretion of calcium and creatinine in relation to age and body weight in normal subjects and patients with renal calculi. Clin Sci, v. 38, p. 60 I-12, 1970.

10. CARTER, G.D. et al. How accurate are assays for 25hydroxyvitamin D? Data from the international vitamin D external quality assessment scheme. Clin Chem, v. 50, p. 2195-7, 2004.

I I. DEMIAUX, B.; ARLOT, M.E.; CHAPUY, M.C. Serum osteocalcin is increased in patients with osteomalacia: correlations with biochemical and histomorphometric findings.J Clin Endocrinol Metab, v. 74, p. I|46-5I, 1992.

12. EASTELL, R. et al. Evaluation of bone turnover in type I osteoporosis using biochemical markers specific for both bone formation and bone resorption. Osteoporos Int, v. 3, p. 255-60, 1993.

13. GARNERO, P. et al. Increased bone turnover in late menopausal women is a major determinant of osteoporosis.J Bone Miner Res, v. II, p. 337-49, 1996.

14. GREENSPAN, S.L.; RESNICK, N.M.; PARKER, R.A. Early changes in biochemical markers of bone turnover are associated with long-term changes in bone mineral density in elderly women on alendronate, hormone replacement therapy, or combination therapy: a three-year, double-blind, placebocontrolled, randomized clinical trial.J Clin Endocrinol Metab, v. 90, p. 2762-7, 2005.

15. HADDAD, J.G.; CHYU, K.J. Competitive protein-binding radioassay for 25-hydroxycolecalciferol. J Clin Endocrinol Metab, v. 33, p. 992-5, 1971.

16. HOLICK, M.F. et al. Prevalence of vitamin D inadequacy among postmenopausal North American women receiving osteoporosis therapy.J Clin Endocrinol Metab, v. 90, p. 321524, 2005.

17. KUSHIDA, K. et al. Comparison of markers for bone formation and resorption in premenopausal and postmenopausal subjects and osteoporotic patients. J Clin Endocrinol Metab, v. 80, p. 2447-50, 1995.

18. LENSMEYER, G.L. et al. HPLC method for 25 hydroxyvitamin D measurement: comparison with contemporary assays. Clin Chem, v. 52, p. I 120-6, 2006.

19. MCLEAN, F.C.; HASTINGS, A.B. The state of calcium in the fluids of the body l: the conditions affecting the ionization of calcium.J Biol Chem, v. 108, p. 285-322, 1935.

20. NIELSEN, H.K. et al. Changes in biochemical markers of osteoblastic activity during the menstrual cycle. J Clin Endocrinol Metab, v. 70, p. 1431-7, 1990.

2I.NUSSBAUM,S.R. et al. Highly sensitive two-site immunoradiometric assay of parathyrin and its clinical utility in evaluating patients with hypercalcemia. Clin Chem, v. 33, p. 1364-7, 1987

22. RAUCH, F.; SCHONAU, E.; WOITGE, H. Urinary excretion of hydroxy-piridinium cross-links of collagen reflects skeletal growth velocity in normal children. Exp Clin Endocrinol, v. 102, p. 94-7, 1994.

23. REINHARDT,T.A. et al.A microassay for 1,25-dihydroxyvitamin $D$ not requiring high performance liquid chromatography: application to clinical studies. J Clin Endocrinol Metab, v. 58, p. $91-8,1984$.

24. SARAINEN, S. et al. Nocturnal rise in markers of bone resorption is not abolished by bedtime calcium or calcitonin. CalcifTissue Int, v. 55, p. 349-52, 1994.

25. SARAIVA, G.L. et al. Influence of ultraviolet radiation on the productin of 25 hydroxyvitamin $D$ in the elderly population in the city of São Paulo (23 degress 34'S), Brazil. Osteoporos Int, v. 16, p. 1649-54, 2005.

26. SEIBEL, M.J. et al. Urinary hydroxypyridinium crosslinks of collagen as markers of bone resoption and strogen efficacy in postmenopausal osteoporosis. J Bone Miner Res, v. 8, p. 881-9, 1993.

27. SOWERS, M.; EYRE, D.; Hollis, B.W. Biochemical markers of bone turnover in lactating and nonlactating postpartum women. J Clin Endocrinol Metab, v. 80, p. 2210-6, 1995.

28. STEIN, G.S.; LIAN, J.B. Molecular mechanisms mediating proliferation/differentiation interrelationships during progressive development of the osteoblast phenotype. Endocrin Rev, v. 14, p. 424-42, 1993.

29. VIEIRA, J.G.H. et al. Os valores de paratormônio obtidos com ensaios imunométricos dependem da especificidade do anticorpo aminoterminal empregado. Arq Bras Endocrinol Metabol, v. 48, p. 5। 8-24, 2004.

30. VIEIRA, J.G.H. et al. Development and clinical application of an immunofluorometric assay for intact parathyroid hormone. Brazilian J Med Biol Res, v. 27, p. 2379-82, 1994.

31. VIEIRA, J.G.H. et al. Análise crítica de dois radioimunoensaios segmento-específicos para a medida de paratormônio no diagnóstico de hiperparatiroidismo primário. Rev Ass Med Brasil, v. 34, p. 79-83, 1988.

32. VIEIRA, J.G.H. et al. Development of an homologous radioimmunoassay for the synthetic amino terminal ( I-34) fragment of human parathyroid hormone using egg yolkobtained antibodies. J Immunoassay, v. 7, p. 57-72, 1986.

33. WISHART, J.M.; NEED, A.G.; HOROWITZ, M. Effect of age on bone density and bone turnover in men. Clin Endocrinol (Oxf), v. 42, p. I4I-6, 1995.

\begin{tabular}{l|l} 
& Endereço para correspondência \\
\hline & Laboratório Fleury \\
& Avenida Ceneral Valdomiro de Lima, 508 \\
CEP: 04344-903 - Jabaquara - São Paulo-SP \\
e-mail: jose.vieira@fleury.com.br
\end{tabular}

